University for Business and Technology in Kosovo

UBT Knowledge Center

UBT International Conference

2012 UBT International Conference

Nov 2nd, 9:00 AM - Nov 3rd, 5:00 PM

\title{
Computer Aided Analysis Of Kinematics And Kinetostatics Of Six- Bar Linkage Mechanism Through The Contour Method
}

Qelaj Mehmet

Ministry of Economic Development, mehmet.qelaj@gmail.com

Likaj Ramë

Ministry of Economic Development, ramelikaj@yahoo.com

Follow this and additional works at: https://knowledgecenter.ubt-uni.net/conference

Part of the Computer Sciences Commons, and the Engineering Commons

\section{Recommended Citation}

Mehmet, Qelaj and Ramë, Likaj, "Computer Aided Analysis Of Kinematics And Kinetostatics Of Six-Bar Linkage Mechanism Through The Contour Method" (2012). UBT International Conference. 68.

https://knowledgecenter.ubt-uni.net/conference/2012/all-events/68

This Event is brought to you for free and open access by the Publication and Journals at UBT Knowledge Center. It has been accepted for inclusion in UBT International Conference by an authorized administrator of UBT Knowledge Center. For more information, please contact knowledge.center@ubt-uni.net. 


\title{
COMPUTER AIDED ANALYSIS OF KINEMATICS AND KINETOSTATICS OF SIX- BAR LINKAGE MECHANISM THROUGH THE CONTOUR METHOD
}

\begin{abstract}
Qelaj Mehmet
Ministry of Economic Development

Mother Theresa Street - No. 36 - 10000 Pristina Technical Faculty, n.n - 10000 Pristina

mehmet.qelaj@gmail.comramelikaj@yahoo.com

\section{Abstract}

In this paper is presented a six-bar linkage mechanism of the pump for oil extrusion. In this mechanism are introduced even higher kinematic pairs. Dimensions and other incoming links will be adopted as necessary. For the six-bar linkage mechanism will be carried out the kinematic analysis and for all linkages will be presented the displacement, velocity and acceleration. The analysis will be performed by MathCad software, while kinetostatic analysis will be carried out using Contour Method, comparing results of two different software's MathCAD and Working Model. The simulation parameters will be computed for all points of the contours of mechanism.
\end{abstract}

Keywords: mechanism, contour, displacement, speed, acceleration

This paper has been realised with two application software's: MathCad and Working Model. In this paper is presented a four-bar linkage $\mathrm{ABCD}$ and a simple crank mechanism DEF as shown in the figure below. In this mechanism firstly is determined $D F_{y}$ and $\theta_{5}$. Derivative $D F_{y}$ represents the speed of the slider $F$. From the given picture $\theta_{2}=0,1, \ldots, 360^{\circ}$ should be determined. The masses are adopted, since the moments of inertia need to calculate. The kinematic part of the paper will be completed by finding the velocities and accelerations of each point $A, B, C, D, E, F$ for the centres from $C_{1}$ to $C_{6}$. In this way are determined the angular accelerations and velocities of the linkages 2, 3, 4 and 5. Whereas for the kinetostatic part will be determined the reaction forces of the points: $X_{A}, Y_{A}, X_{B}, Y_{B}, X_{C}, Y_{C}, X_{D}, Y_{D}, X_{E}, Y_{E}, X_{F}$, $Y_{F}, N=X_{F 6}$ and $M_{t r}$ which are acting on the leading link 2. In the picture are shown 5 bodies: $A B, B C$, right triangle, rod $\mathrm{EF}$, slider bar $\mathrm{F}$.

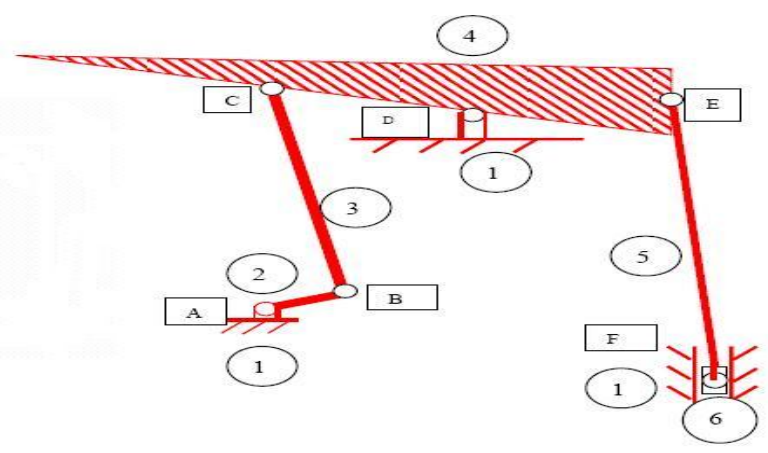

Given data:

Figure 1: Six bar-linkage mechanism $A B C D E F$

$$
\begin{array}{llll}
\theta_{2}:=0,5 \mathrm{deg} . .360 \mathrm{deg} & \omega_{2}:=2 \\
\mathrm{r}_{2}:=1.7 & \mathrm{r}_{3}:=6.9 & \mathrm{r}_{4 \mathrm{a}}:=4.2 & \mathrm{r}_{4 \mathrm{~b}}:=4.0 \quad \mathrm{r}_{5}:=9.2 \quad \mathrm{r}_{\mathrm{D}}:=\sqrt{4.2^{2}+6.4^{2}}
\end{array}
$$


Determination of angle $\alpha$ of $r_{D}$ with $x_{1}$ :

$$
\alpha:=\operatorname{acos}\left(\frac{4.2}{\sqrt{4.2^{2}+6.4^{2}}}\right) \quad \frac{\alpha}{\mathrm{deg}}=56.725
$$

$$
\begin{aligned}
& \text { Linkage I } \\
& \overrightarrow{\mathrm{r}_{2}}+\overrightarrow{\mathrm{r}_{3}}+\overrightarrow{\mathrm{r}_{4 \mathrm{a}}}=\overrightarrow{\mathrm{r}_{\mathrm{D}}}
\end{aligned}
$$

From then designed outline at $x$ and $y$ we have the following initial conditions:

Given

$$
\begin{aligned}
& \mathrm{r}_{2} \cdot \cos \left(\theta_{2}\right)+\mathrm{r}_{3} \cdot \cos \left(\theta_{3}\right)+\mathrm{r}_{4 a} \cdot \cos \left(\theta_{4}\right)=\mathrm{r}_{\mathrm{D}} \cdot \cos (\alpha) \\
& \mathrm{r}_{2} \cdot \sin \left(\theta_{2}\right)+\mathrm{r}_{3} \cdot \sin \left(\theta_{3}\right)+\mathrm{r}_{4 a} \cdot \sin \left(\theta_{4}\right)=\mathrm{r}_{\mathrm{D}} \cdot \sin (\alpha)
\end{aligned}
$$

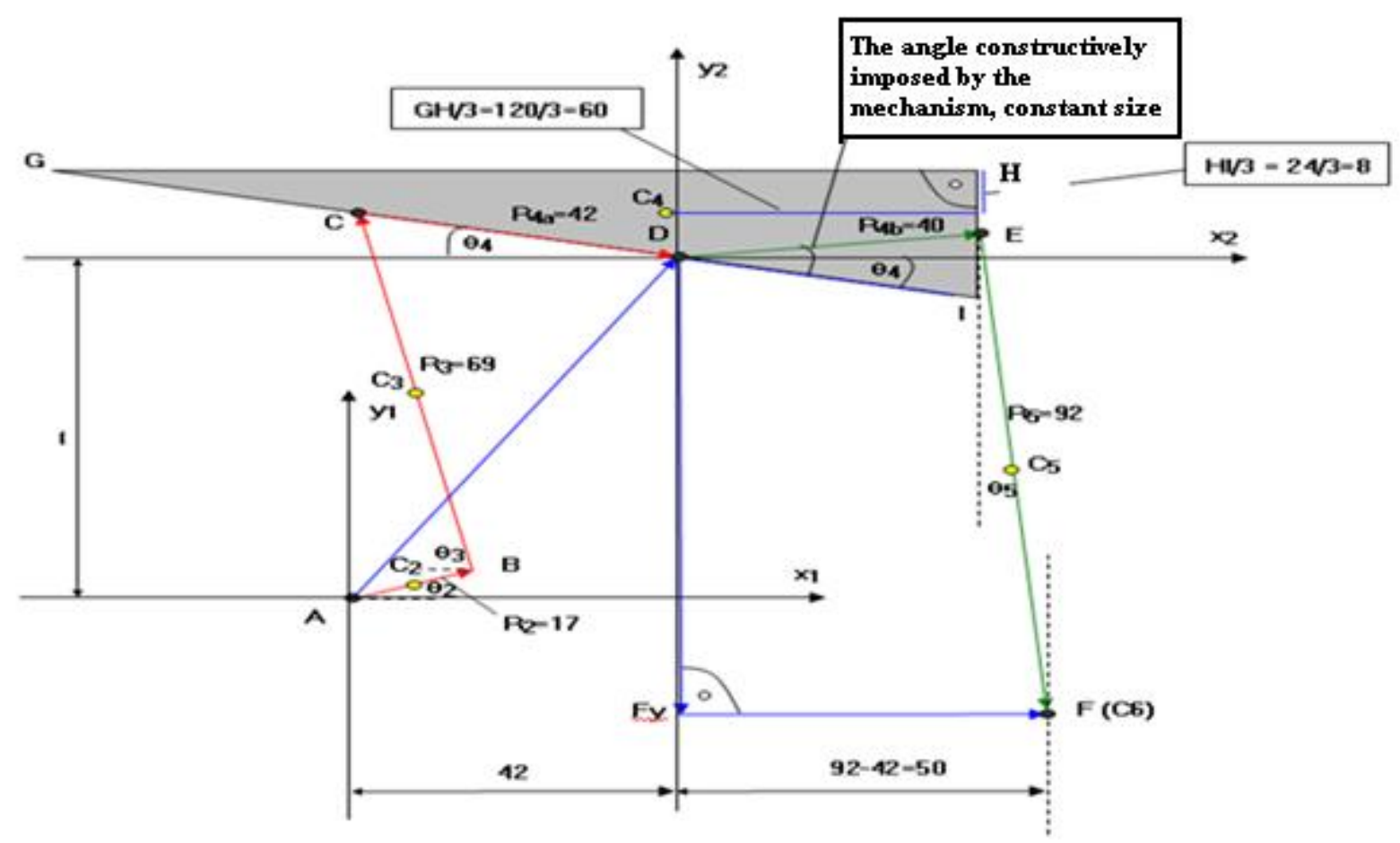

Figure 2: Four-bar linkage $A B C D$ and crank mechanism $D E F$

As shown in the Figure 2, there are 14 unknown sizes, 12 equations for the first four bodies, $d y(x, y)$ for the slider 14 equations.

1.1 The analysis of the positions, velocities and accelerations of six-bar linkage mechanism In the figure 3 is presented the velocity plan for the points $A, B, C$ and $D$. Also are presented angular velocities and angular accelerations for the points $A, B$ and $C$. After finding the velocities and accelerations of these points, the displacements, velocities and accelerations of these points with angles $\theta_{3}$ and $\theta_{4}$ in function of $\left(\theta_{2}\right)$ are shown graphically. Outline is shown in this form: 


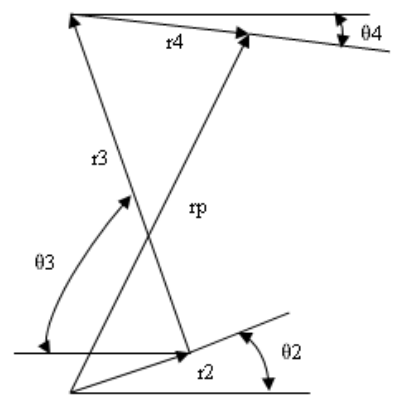

Figure 3: Velocity plan for the points $A, B$ and $C$

Given $\theta 3:=180 \cdot \mathrm{deg}$

$\theta 4:=90 \cdot \mathrm{deg}$

Ekuacioni vektorial për konturin I:

$$
\begin{aligned}
& \left(\begin{array}{c}
12 \cdot \cos (\theta 2) \\
12 \cdot \sin (\theta 2) \\
0
\end{array}\right)+\left(\begin{array}{c}
13 \cdot \cos (\theta 3) \\
13 \cdot \sin (\theta 3) \\
0
\end{array}\right)+\left(\begin{array}{c}
14 \cdot \cos (\theta 4) \\
14 \cdot \sin (\theta 4) \\
0
\end{array}\right)=\left(\begin{array}{c}
\mathrm{pp} \cdot \cos (\alpha) \\
\mathrm{rp} \cdot \sin (\alpha) \\
0
\end{array}\right) . \\
& Z g(\theta 2):=\operatorname{Find}(\theta 3, \theta 4) \\
& \theta 3(\theta 2):=Z \operatorname{gj}(\theta 2) 0 \\
& \theta 4(\Theta 2):=Z_{g j}(\theta 2) \\
& \beta:=\operatorname{asin}\left(\frac{2.4}{\sqrt{1.2^{2}+2.4^{2}}}\right) \quad \frac{\beta}{\operatorname{deg}}-\frac{-\theta 4(0)}{\operatorname{deg}}=59.478 \\
& \frac{\theta 3(0)}{\operatorname{deg}}=104.177 \\
& \frac{\theta 4(0)}{\operatorname{deg}}=-3.957 \\
& \omega_{3}(\theta 2):=\frac{d}{d \theta 2} \theta 3(\theta 2) \cdot \omega 2 \\
& \omega_{4}(\theta 2):=\frac{d}{d \theta 2} \theta 4(\theta 2) \cdot \omega 2 \\
& \varepsilon_{3}(\theta 2):={\frac{d^{2}}{d \theta 2^{2}}}^{\theta 3(\theta 2) \cdot \omega 2^{2}} \\
& \varepsilon_{4}(\theta 2):={\frac{d^{2}}{d \theta 2^{2}}}^{\theta 4(\theta 2) \cdot \omega 2^{2}}
\end{aligned}
$$

After calculation of the values by MathCad software, in the following are shown graphically the values of positions, velocities and accelerations respectively for $\theta_{3}, \omega_{3} \varepsilon_{3}$ and $\theta_{4}, \omega_{4}, \varepsilon_{4}$ :

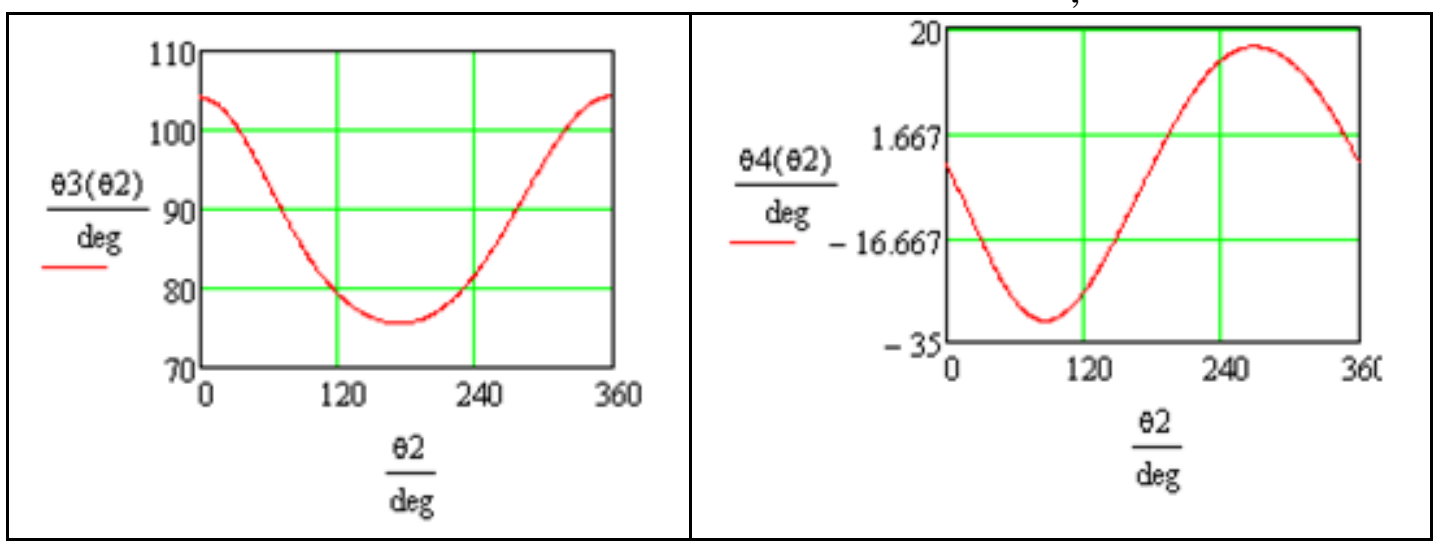




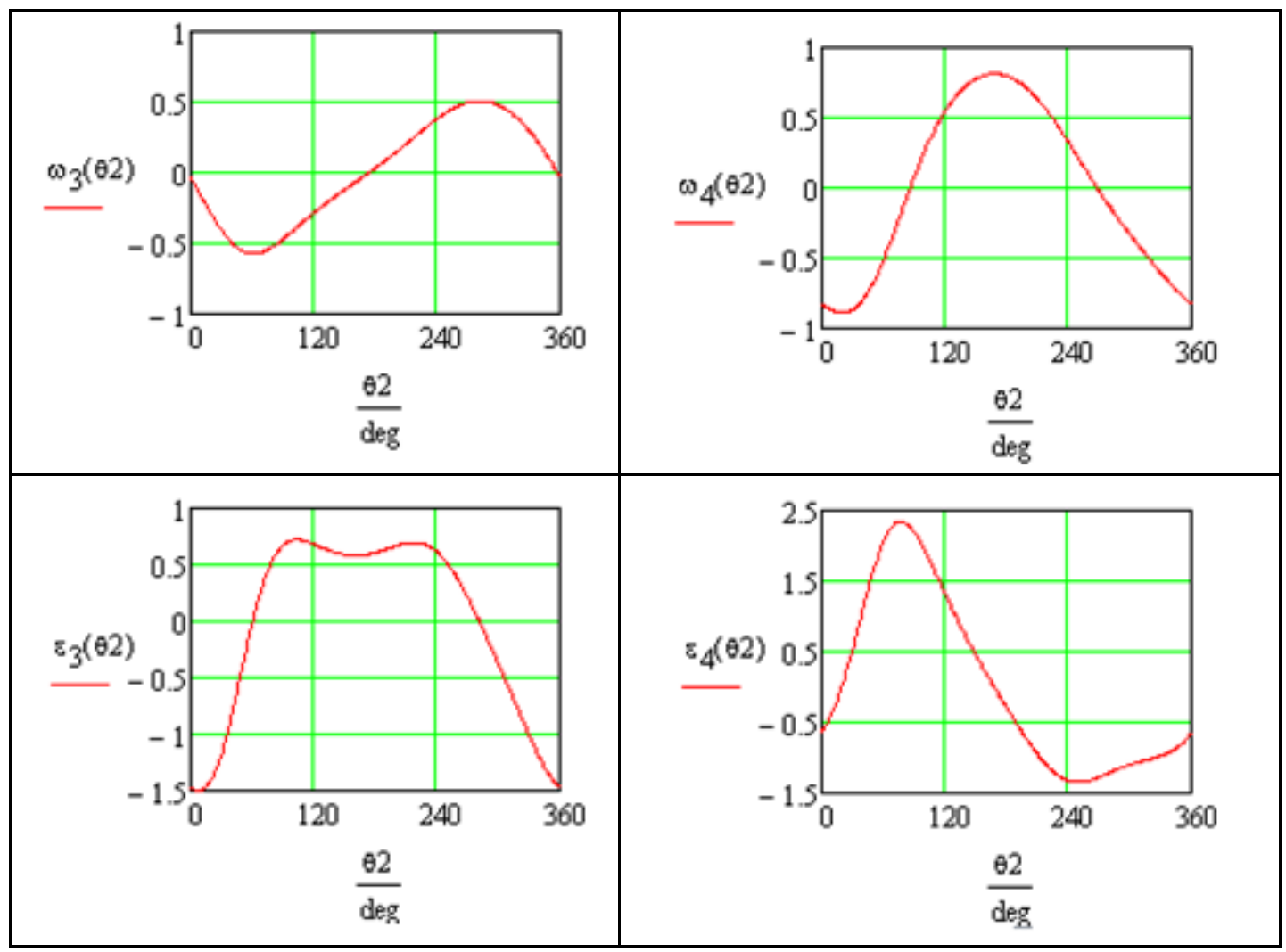

Figure 4: Diagrams for positions, velocities and accelerations

\subsection{Position of the point $B$}

The position of the point $\mathrm{B}$ is calculated in direction of $x$ and $y$ :

$$
\begin{array}{ll}
\mathrm{x}_{\mathrm{B}}(\theta 2):=\mathrm{r2} \cdot \cos (\theta 2) & \mathrm{y}_{\mathrm{B}}(\theta 2):=\mathrm{r2} \cdot \sin (\theta 2) \\
\mathrm{v}_{\mathrm{BX}}(\theta 2):=-\mathrm{r2} \cdot \sin (\theta 2) \cdot \omega 2 & \mathrm{v}_{\mathrm{By}}(\theta 2):=\mathrm{r} \cdot \cos (\theta 2) \cdot \omega 2 \\
\mathrm{v}_{\mathrm{B}}(\theta 2):=\sqrt{\mathrm{v}_{\mathrm{BX}}(\theta 2)^{2}+\mathrm{v}_{\mathrm{By}}(\theta 2)^{2}} & \sqrt{9.2^{2}+40^{2}}=10.032
\end{array}
$$

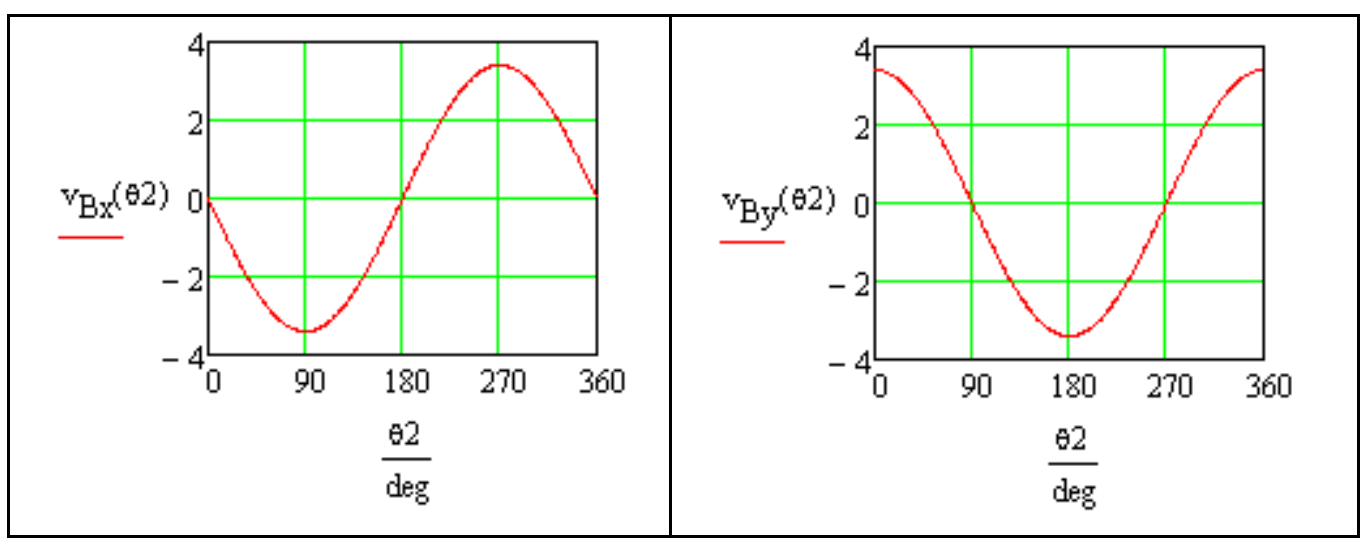




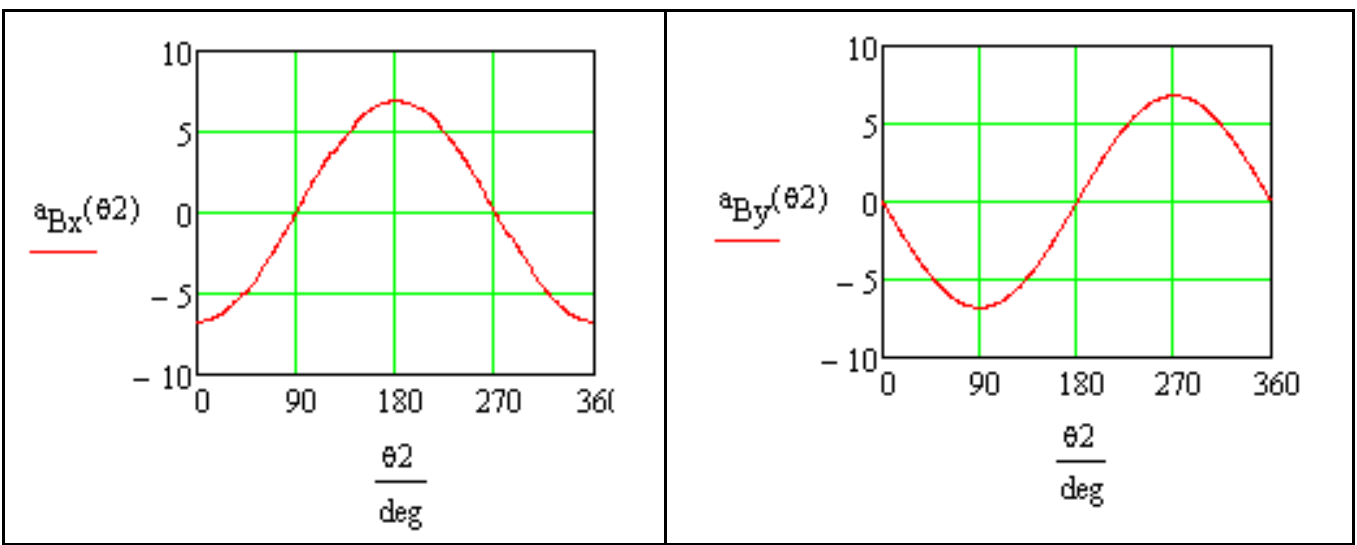

Figure 5: The position diagrams for the position equations of the point $B$ in direction of $x$ and $y$

$$
\begin{gathered}
{ }^{{ }_{B}}(\theta 2):=-12 \cdot \cos (\theta 2) \cdot \omega 2^{2} \\
{ }^{a} B y(\theta 2):=-12 \cdot \sin (\theta 2) \cdot \omega 2^{2} \\
{ }^{a}{ }_{B}(\theta 2):=\sqrt{{ }^{a} B x(\theta 2){ }^{2}+{ }^{a} \mathrm{By}(\theta 2)^{2}}
\end{gathered}
$$

Angular velocity and acceleration for the point $B$ :

$$
\begin{array}{ll}
\omega_{4}(\theta 2):=\frac{d}{d \theta 2} \theta 4(\theta 2) \cdot \omega 2 & z_{A}(\theta 2):={\frac{d^{2}}{d \theta 2^{2}}}^{\theta 4(\theta 2) \cdot \omega 2^{2}} \\
\omega_{4}(0.5)=-0.87 & \varepsilon_{4}(0.5)=0.445
\end{array}
$$

\subsection{The equations for position (displacement), velocity and acceleration of the point $\mathrm{C}$}

In the following is shown the displacement of point $\mathrm{C}$, along with velocities and accelerations which are presented graphically by the diagrams via MathCad programme:

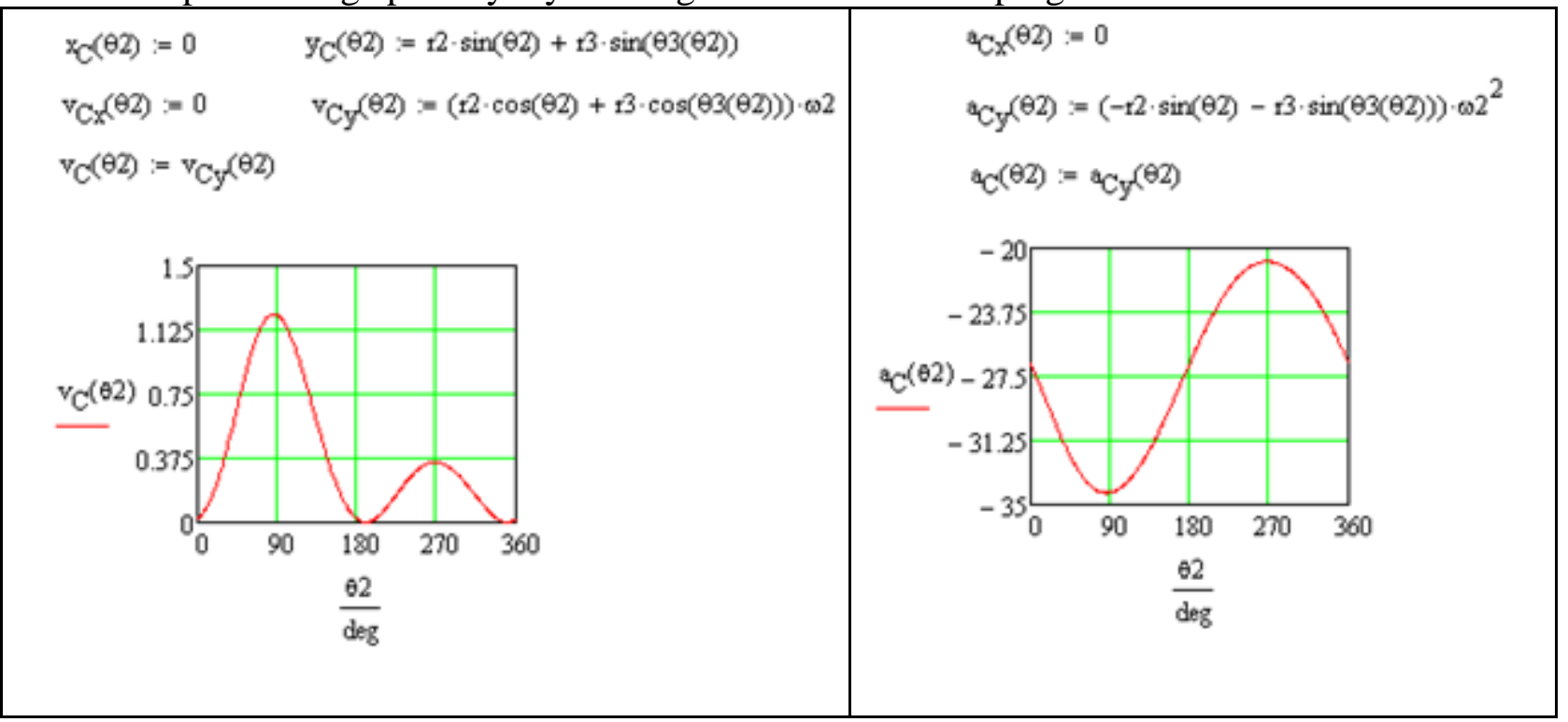


Figure 6 Velocities and acceleration of point $C$

1.4 The expression for the middle point of the bars $A B, B C$ and $C D$

In the following are extracted the displacement for the middle position of the bars $A B, B C$ and $C D$ and other displacement which belong to these bars. Are also presented the velocities and accelerations of these bars and their diagrams separately:

$$
\begin{aligned}
& { }^{x} \cos (\theta 2)=\frac{12}{2} \cdot \cos (\theta 2) \\
& y_{C 2}(62)=\frac{i z}{2} \cdot \sin (\theta 2) \\
& 2 \cos (\theta 2)=\frac{-12}{2} \cdot \cos (\theta 2) \cdot \omega 2^{2} \\
& \operatorname{scz}(\theta 2)=\frac{-12}{2} \cdot \sin (\theta 2) \cdot 02^{2} \\
& \text { BC } \\
& x^{x} \operatorname{Cs}(\theta 2)=\frac{13}{2} \cdot \cos (\theta 3(\theta 2)) \\
& y_{C 3}(\theta 2)=\frac{13}{2} \cdot \sin (\theta 3(\theta 2)) \\
& 3 \cos (\theta 2)=\frac{-3}{2} \cdot \cos (\theta \operatorname{\theta in}(\theta 2)) \cdot \omega 2^{2} \\
& \operatorname{syc}(\theta 2)=\frac{-13}{2} \cdot \sin (\theta 3(\theta z))-\omega 2^{2} \\
& \text { CD } \\
& x_{C}(\theta 2)=\frac{x^{4}}{2} \cdot \cos (\theta 4(\theta 2)) \\
& y_{C 4}(\theta 2)=\frac{74}{2} \cdot \sin (\theta 4(\theta 2)) \\
& \operatorname{scc}(\theta 2)=\frac{-74}{2} \cdot \cos (\theta 4(\theta 2)) \cdot \omega 2^{2} \\
& y_{C 4}(\theta 2)=\frac{-74}{2} \cdot \sin (\theta 4(\theta 2))-\omega 2^{2}
\end{aligned}
$$

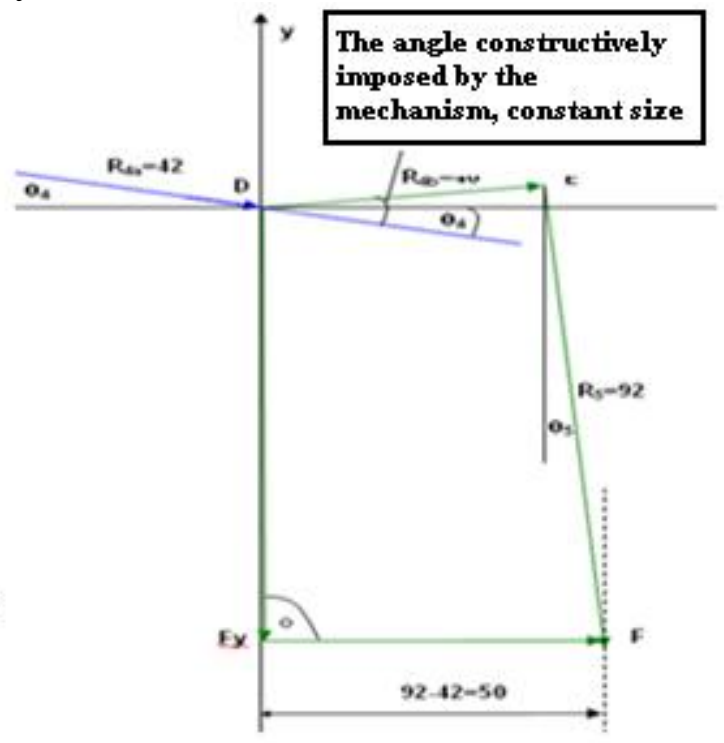

Figure 7: Crank mechanism

\subsection{The equations for position (displacement), velocity and acceleration of the point $E$}

For the point $E$ of Crank Mechanism determined the displacement, and in the following pictures are shown velocities and accelerations in the direction $x$ and $y$ :

$$
\begin{array}{ll}
\mathrm{x}_{\mathrm{E}}(\theta 2):=14 \mathrm{~b} \cdot \cos (\theta 4(\theta 2)) & \mathrm{y}_{\mathrm{E}}(\theta 2):=r 4 \mathrm{~b} \cdot \sin (\theta 4(\theta 2)) \\
\mathrm{v}_{\mathrm{EX}}(\theta 2):=-14 \mathrm{~b} \cdot \sin (\theta 4(\theta 2)) \cdot \omega 2 & \mathrm{v}_{\mathrm{EV}}(\theta 2):=r 4 \mathrm{~b} \cdot \cos (\theta 4(\theta 2)) \cdot \omega 2 \\
{ }^{\mathrm{a}} \mathrm{ax}(\theta 2):=-14 \mathrm{~b} \cdot \cos (\theta 4(\theta 2)) \cdot \omega 2^{2} & { }^{\mathrm{a}} \mathrm{EX}(\theta 2):=-14 \mathrm{~b} \cdot \sin (\theta 4(\theta 2)) \cdot \omega 2^{2}
\end{array}
$$

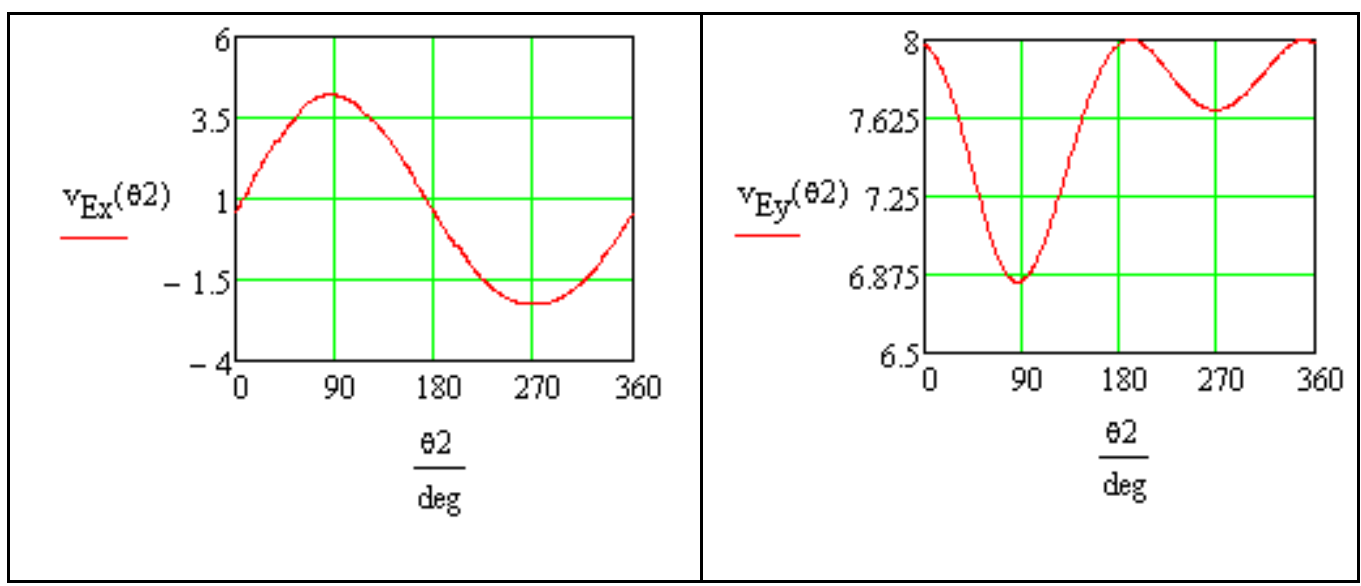




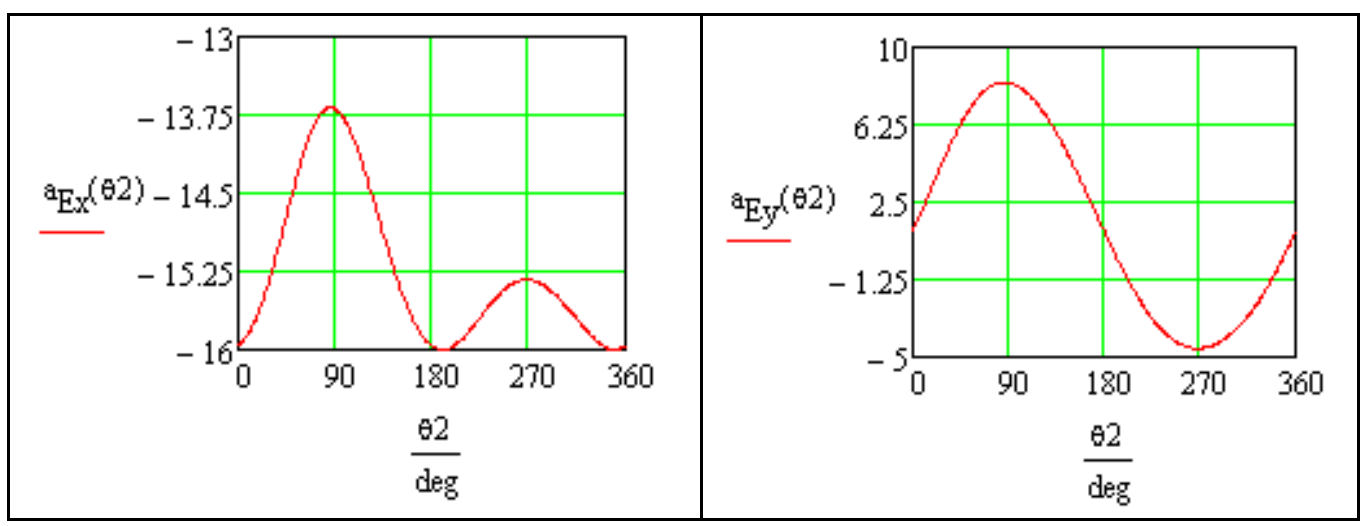

Figure 8: Diagrams of the velocities and acceleration for the $E$

\subsection{Kinetostatic analysis of the six-bar linkage mechanism}

For the kinetostatic part will be presented the kinetostatic analysis of six-bar linkage mechanism by MathCad software. Moments of inertia, masses of bodies are used in the following:

$$
\begin{gathered}
\mathrm{m} 2:=10 \quad \mathrm{~m} 3:=15 \quad \mathrm{~m} 4:=20 \quad \mathrm{~ms}:=15 \quad \mathrm{~m} 6:=5 \quad \mathrm{~g}:=9.807 \\
\mathrm{~J}_{\mathrm{C} 2}:=\frac{1}{12} \cdot \mathrm{m} 2 \cdot \mathrm{r}^{2} \quad \mathrm{~J}_{\mathrm{C} 3}:=\frac{1}{12} \cdot \mathrm{m}^{2} \cdot \mathrm{r}^{2} \quad \mathrm{~J}_{\mathrm{C} 4}:=\frac{1}{18} \mathrm{~m} 4\left(2.4^{2}+1.2^{2}\right) \\
\mathrm{J}_{\mathrm{C} 5}:=\frac{1}{12} \cdot \mathrm{m5} \cdot \mathrm{r}^{2} \quad \frac{1}{12} \mathrm{~m} 4\left(2.4^{2}+12^{2}\right)=249.6
\end{gathered}
$$

\section{Linkage I}

The equilibrium conditions for the point $A$ are equal to zero. Six linkages are used for the kinetostatic analysis. For the first linkage are given the following equilibrium conditions $X_{A}, Y_{A}$ and $X_{B}, Y_{B}$ and for the middle points of the linkage $A B$, point $C_{2}$ and for the body mass $m_{2}$.

$$
\begin{aligned}
& \mathrm{X}_{\mathrm{A}}:=0 \quad \mathrm{Y}_{\mathrm{A}}:=0 \quad \mathrm{X}_{\mathrm{B}}:=0 \quad \mathrm{Y}_{\mathrm{B}}:=0 \quad \mathrm{X}_{\mathrm{C}}:=0 \quad \mathrm{Y}_{\mathrm{C}}:=0 \quad \mathrm{X}_{\mathrm{D}}:=0 \quad \mathrm{Y}_{\mathrm{D}}:=0 \\
& \mathrm{X}_{\mathrm{E}}:=0 \quad \mathrm{Y}_{\mathrm{E}}:=0 \quad \mathrm{X}_{\mathrm{F}}:=0 \quad \mathrm{Y}_{\mathrm{F}}:=0 \quad \mathrm{NN}:=0 \quad \mathrm{M}_{\mathrm{tr}}:=0
\end{aligned}
$$

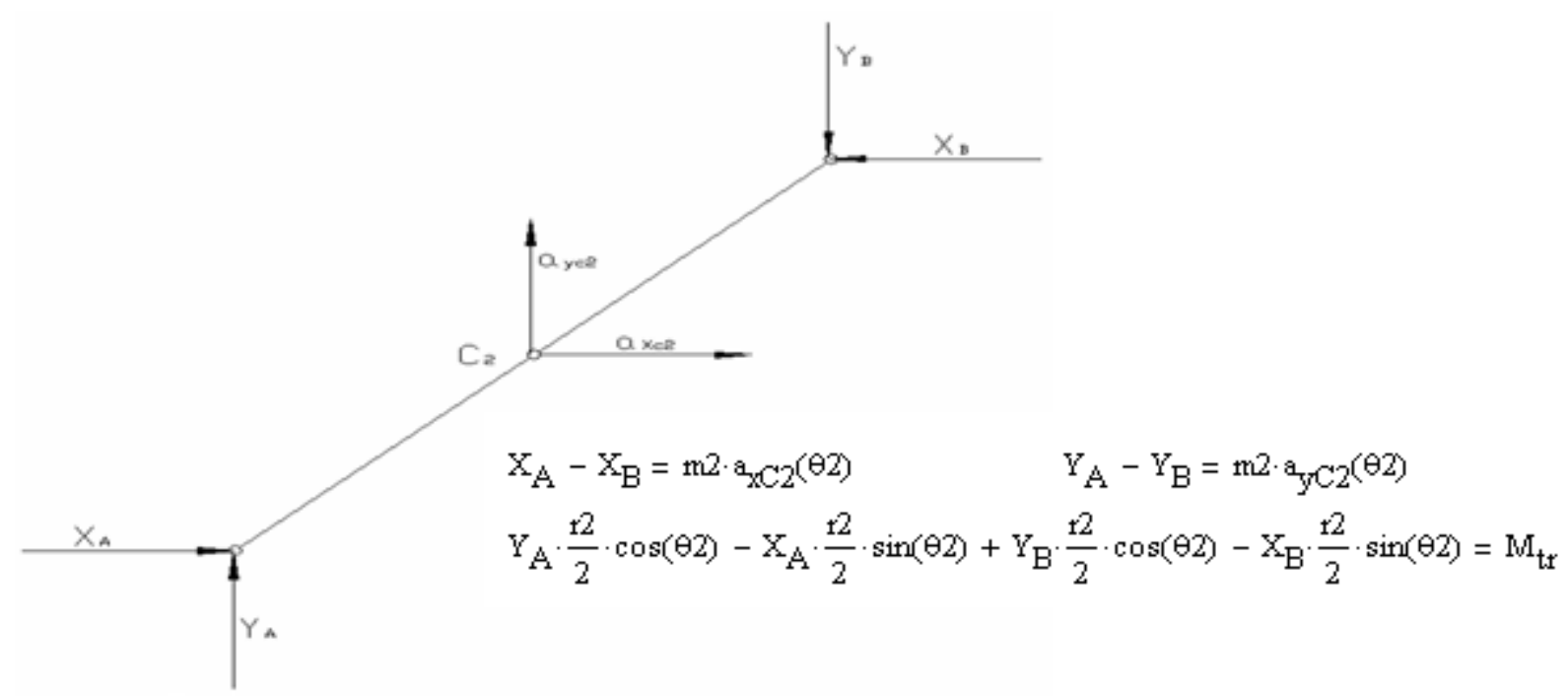




\section{Linkage II}

Figure 9: Linkage I-Equilibrium conditions for the point $A B$

Also, for the linkage II are written the equilibrium conditions $B C$, which are $X_{B}, Y_{B}, X_{C}, Y_{C}$, centre $C_{3}$, body mass $B C$ and moment of inertia for the point $C_{3}$.

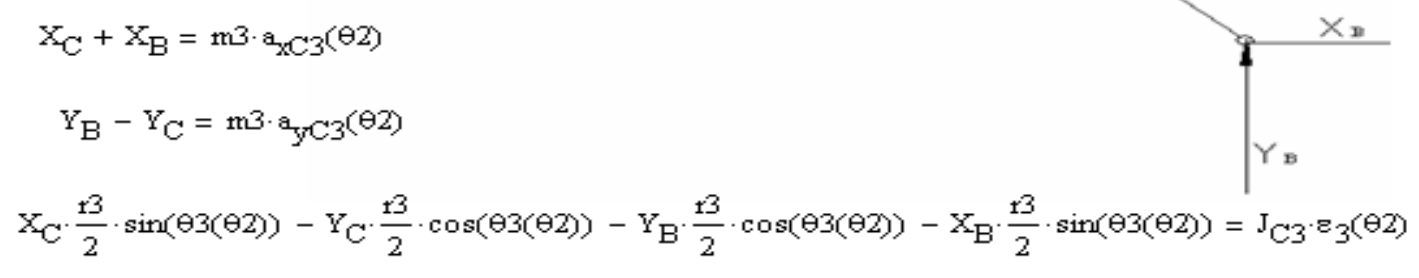

\section{Linkage III}

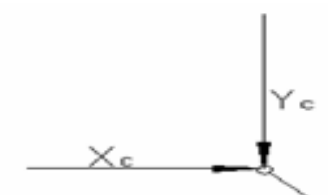

Figure 10: Linkage II - Equilibrium conditions for the part $B C$

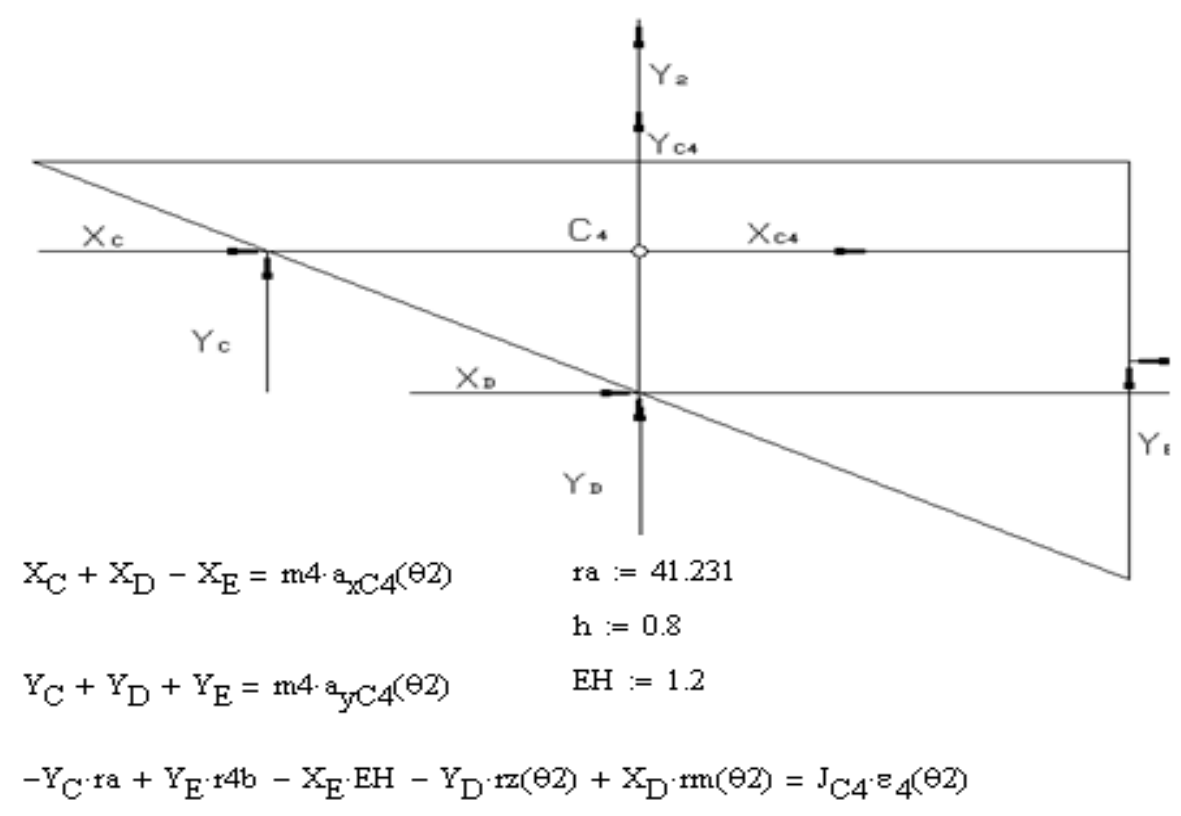

Figure 11: Linkage III of the points $C, D, E$ and centre $C_{4}$ 


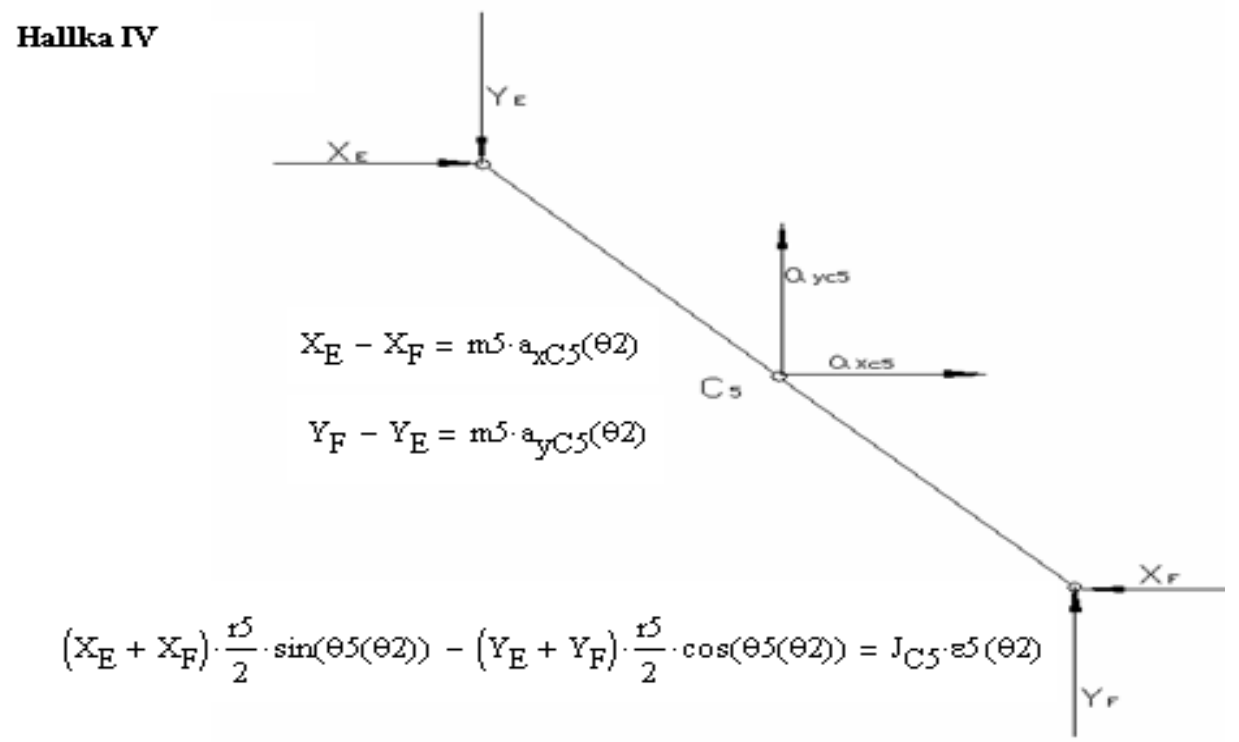

Figure 12: Linkage IV of the part $E F$ in direction of $x$ and $y$

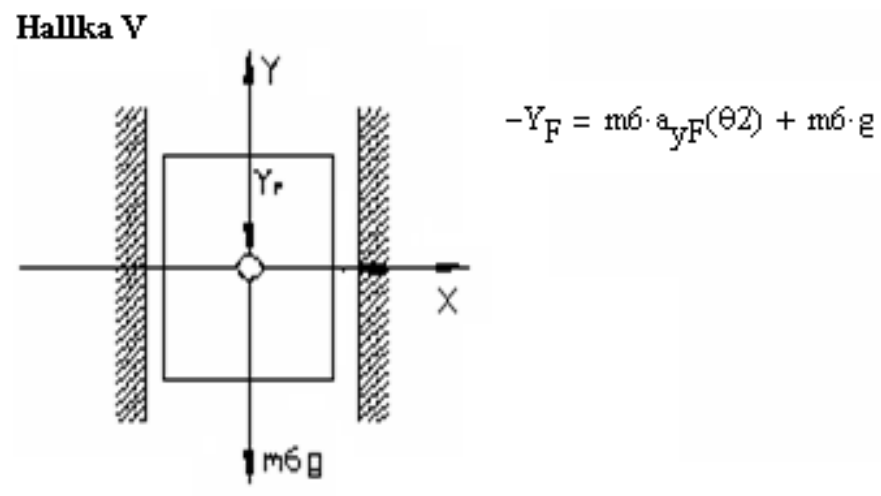

Figure 13: Linkage $\mathbf{V}$ of the point $\mathbf{F}$ in direction of $x$ and $y$

All unknown parameters for the linkages in both directions $\mathrm{x}$ and $\mathrm{y}$ are calculated by MathCad. From point $A$ to the point $F$ and the Transmission moment $M_{t r}$ :

$$
\begin{aligned}
& Z_{\operatorname{gij}}(\theta 2):=\operatorname{Find}\left(\mathrm{X}_{\mathrm{A}}, \mathrm{Y}_{\mathrm{A}}, \mathrm{X}_{\mathrm{B}}, \mathrm{Y}_{\mathrm{B}}, \mathrm{X}_{\mathrm{C}}, \mathrm{Y}_{\mathrm{C}}, \mathrm{X}_{\mathrm{D}}, \mathrm{Y}_{\mathrm{D}}, \mathrm{X}_{\mathrm{E}}, \mathrm{Y}_{\mathrm{E}}, \mathrm{X}_{\mathrm{F}}, \mathrm{Y}_{\mathrm{F}}, \mathrm{M}_{\mathrm{tr}}\right) \\
& X_{A}(\theta 2):=Z g i(\theta 2)_{0} \quad Y_{A}(\theta 2):=Z g i(\theta 2)_{1} \\
& \mathrm{X}_{\mathrm{E}}(\theta 2):=Z_{\mathrm{g} j(}(\theta 2)_{2} \quad \mathrm{Y}_{\mathrm{B}}(\theta 2):=Z_{\mathrm{gi}}(\theta 2)_{3}
\end{aligned}
$$

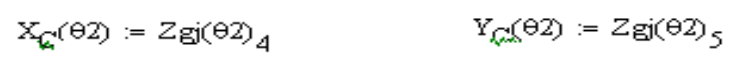

$$
\begin{aligned}
& \mathrm{X}_{\mathrm{R}}(\theta 2):=Z_{\mathrm{gi}}(\theta 2)_{6} \quad \mathrm{Y}_{\mathrm{DQ}}(\theta 2):=Z_{\mathrm{gj}}(\theta 2)_{7} \\
& \mathrm{X}_{\mathrm{k}}(\theta 2):=Z_{\mathrm{gij}}(\theta 2)_{8} \quad \mathrm{Y}_{\mathrm{g}}(\theta 2):=Z_{\mathrm{gij}}(\theta 2)_{9} \\
& X_{F}(\theta 2):=Z_{g}(\theta 2){ }_{10} \quad Y_{F}(\theta 2):=Z_{g i j}(\theta 2){ }_{11} \\
& M_{+x_{s}}(\theta 2):=Z_{g j(}(\theta 2) 12
\end{aligned}
$$

In the following diagrams are given the values of all unknown parameters for the positions $(0$; 0.5 ; 1) by MathCad software. This it was really a tough work since the working process by MathCad was very slow especially to follow the procedure which is given by kinetostatic analysis. 


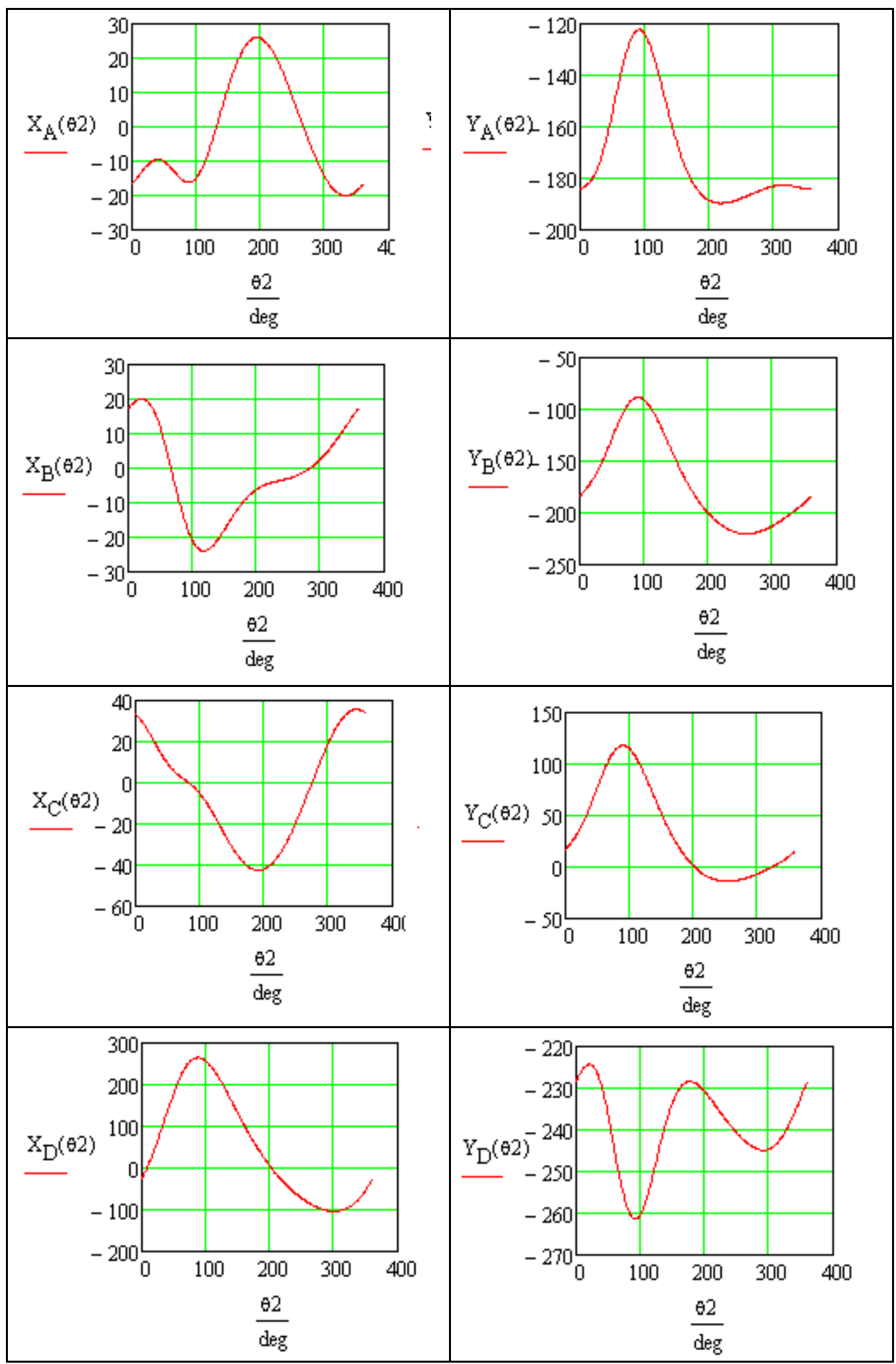




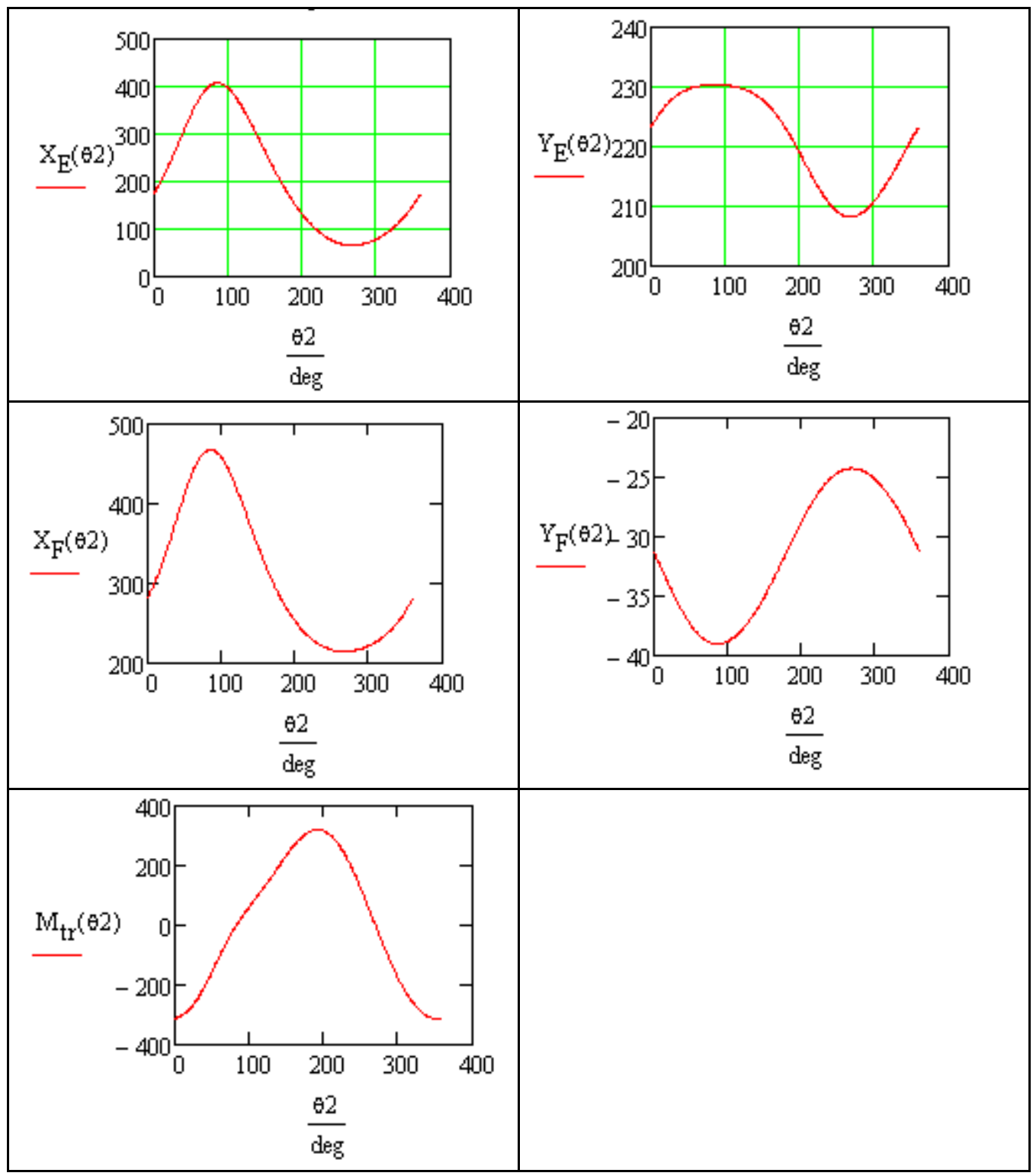

Figure 14: Diagrams of kinetostatic analysis of the given mechanism for the points $A, B, C, D, E, F$ and transmission moment $M_{t r}$

\section{Simulation for six-bar mechanism by Working Model software}

In the second part of this paper is carried out the simulation for all points $A, B, C, D, E, F$ and $M_{t r}$ (time dependent) of the six bar linkage mechanism by Working Model, which is shown in the following. 


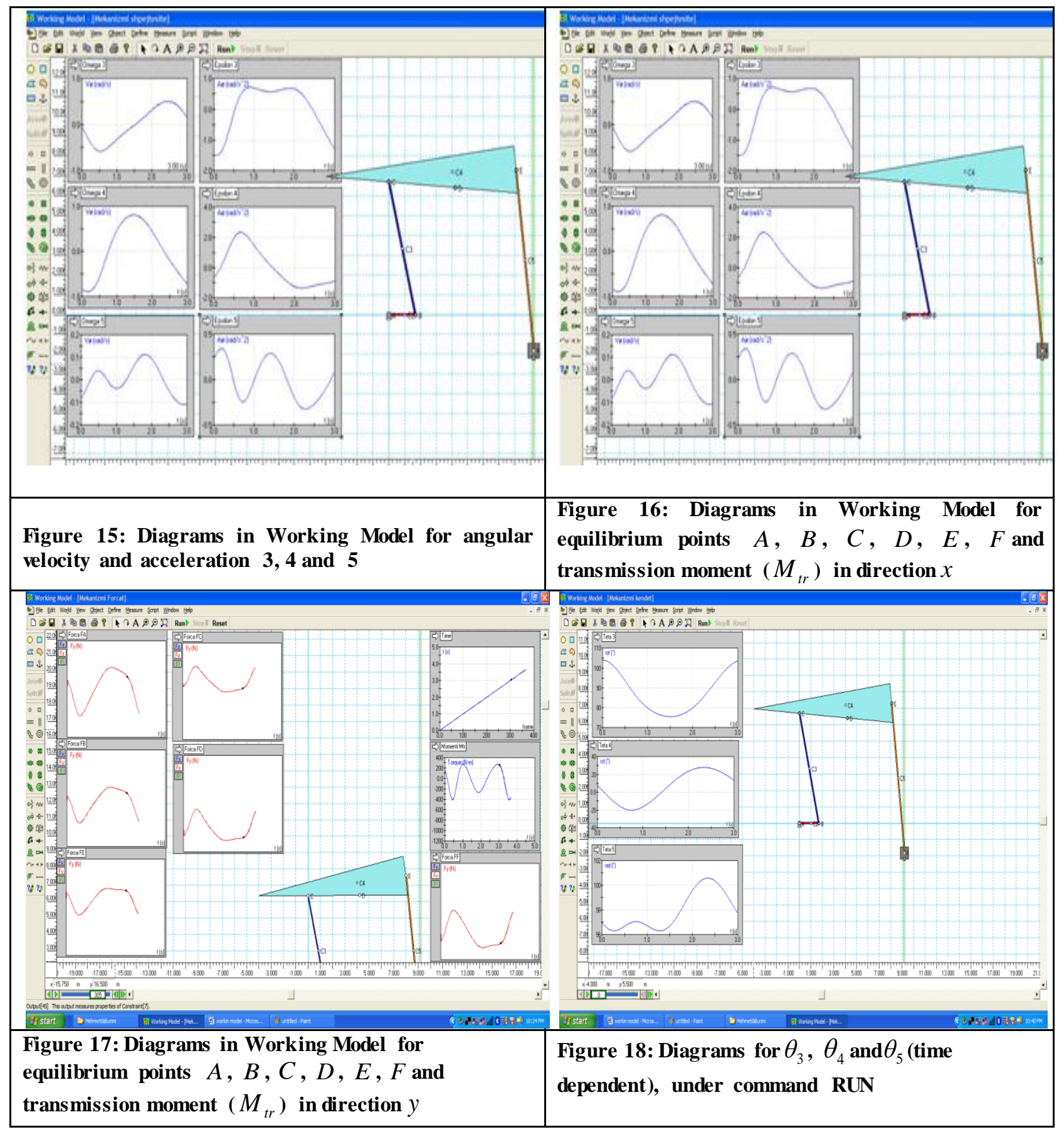

1. Conclusions and recommendations

- By application of the software's MathCad or MatLab we have reached to carry out the full analysis of this paper. In this paper are made the calculations of all positions (displacement) for the whole mechanism, and also are determined the plans for velocities and accelerations for each point.

- However, in this paper are shown the outline planes of the mechanism same as the diagrams for each linkage through MathCadand Working Model software, 
- Six-bar linkage mechanism diagrams which are derived by Working Model are almost similar to the diagrams derived by MathCad, same as the derived results,

- Through Working Model software, are derived the results of reactions from the equilibrium conditions of six bar linkage mechanism, angular velocities and accelerations for the points 3,4 and 5, for the angles $\theta_{3}, \theta_{4}$ and $\theta_{5}$ in time domain through the command Run,

- As the general conclusion; the results derived by both software, same as for their diagrams, for all points of the six bar linkage mechanism are within the reasonable boundaries. Our expectations are that similar results will be derived by application of MatLab software.

\section{References}

[1] Qelaj M: (2008), Punim seminarik, Llogaritja kinematike dhe kinetostatike e mekanizmit gjashtë hallkësh me anën e metodës së konturit me ndihmën e programit MathCad - FIM,

[2] Qelaj M: (2008), Punim seminarik, Llogaritja kinematike dhe kinetostatike e mekanizmit gjashtë hallkësh me ndihmën e programit Working Model, FIM, Prishtinë,

[3] Shala A: (2008), Disenjimi i Mekanizmave me Kompjuter, Ushtrime detyrash - Fakulteti i Inxhinierisë Mekanike, Prishtinë. 